\title{
Structural Sizing Methodology for the Tendon-Actuated Lightweight In-Space MANipulator (TALISMAN) System
}

\author{
Thomas C. Jones ${ }^{1}$, John T. Dorsey ${ }^{2}$ and William R. Doggett ${ }^{3}$ \\ NASA Langley Research Center, Hampton, VA, 23681
}

\begin{abstract}
The Tendon-Actuated Lightweight In-Space MANipulator (TALISMAN) is a versatile long-reach robotic manipulator that is currently being tested at NASA Langley Research Center. TALISMAN is designed to be highly mass-efficient and multi-mission capable, with applications including asteroid retrieval and manipulation, in-space servicing, and astronaut and payload positioning. The manipulator uses a modular, periodic, tension-compression design that lends itself well to analytical modeling. Given the versatility of application for TALISMAN, a structural sizing methodology was developed that could rapidly assess mass and configuration sensitivities for any specified operating work space, applied loads and mission requirements. This methodology allows the systematic sizing of the key structural members of TALISMAN, which include the truss arm links, the spreaders and the tension elements. This paper summarizes the detailed analytical derivations and methodology that support the structural sizing approach and provides results from some recent TALISMAN designs developed for current and proposed mission architectures.
\end{abstract}

\section{Nomenclature}

$=$ cross-sectional area

$=$ width of truss link and I-beam spreader webbing

$=$ Asteroid Redirect Mission

$=$ Asteroid Retrieval Vehicle

$=$ buckling coefficient (end fixity)

$=$ warping stiffness

$=$ Commercial Off-The-Shelf

$=$ principle diameters of boulder

$=$ tab width on cutout webbing of open-section I-beam

$=$ percent deflection

$=$ tip deflection

$=$ modulus of elasticity

$=$ Extra-Vehicular Activity

$=$ internal member load

$=$ kick load

$=$ applied tip loads in the principle directions

$=$ shear modulus

$=$ total height of spreader

$=$ height of closed-section side of spreader

$=$ height of open-section side of spreader

$=$ polar area moment of inertia

$=$ area moment of inertia

= Jacobian Matrix

$=$ Pseudo-Inverse Jacobian

$=$ length of a structural member

$=$ length of moment arm in bending

$=$ length of a single link

\footnotetext{
${ }^{1}$ Research Engineer, Structural Mechanics and Concepts Branch, MS 190, Member, AIAA.

${ }^{2}$ Senior Research Engineer, Structural Mechanics and Concepts Branch, MS 190, Associate Fellow, AIAA.

${ }^{3}$ Senior Research Engineer, Structural Mechanics and Concepts Branch, MS 190, Associate Fellow, AIAA.
} 


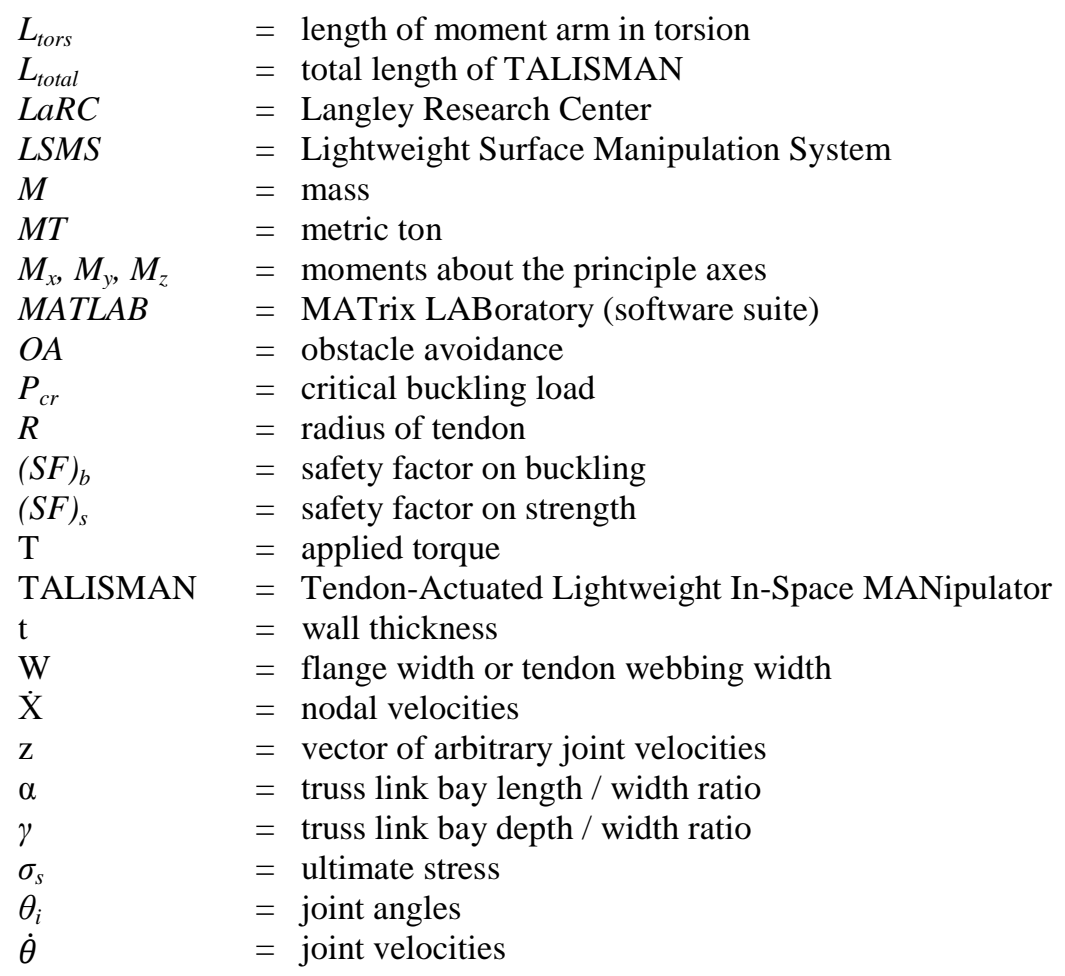

\section{Introduction}

JASA Langley Research (LaRC) Center has been studying long-reach, tendon-actuated manipulators for a decade. During the constellation program (2005-2009), there was a need for a versatile, dexterous manipulator that could offload payloads from the Altair lunar lander and that could also perform additional tasks on the lunar surface $^{1}$. The Lightweight Surface Manipulation System (LSMS) was designed to meet these needs (Fig. 1a) and provided a highly mass-efficient approach to performing multiple tasks including payload positioning, digging, forklift operations, grappling and precision welding ${ }^{1,2}$. The modular, periodic, tension-compression design of the LSMS

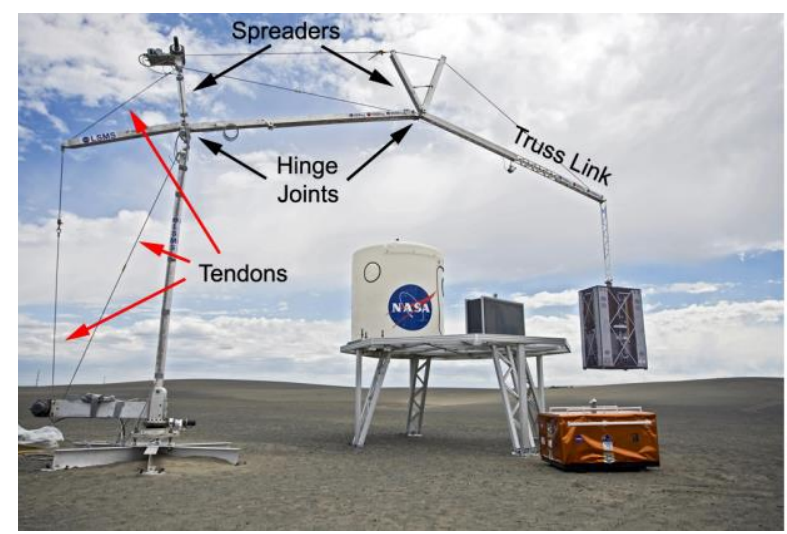

a) LSMS during field testing at Moses Lakes, WA.

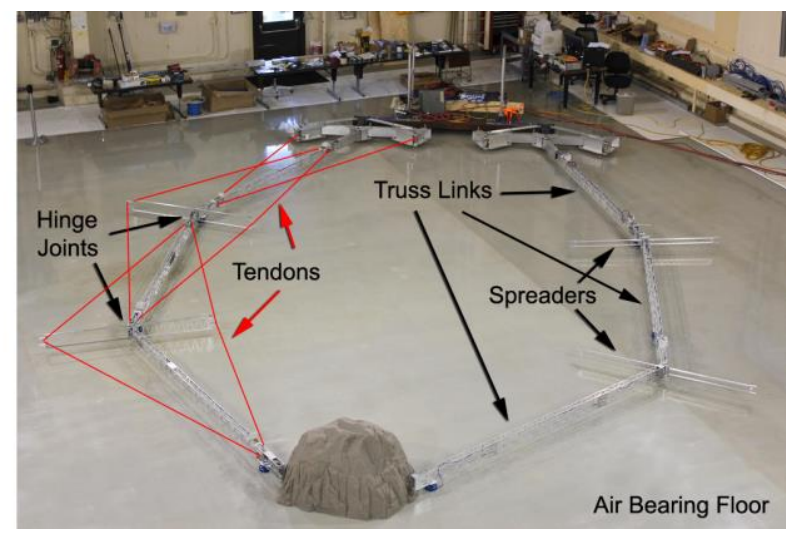

b) TALISMAN prototypes at NASA LaRC.

Figure 1. Long-reach manipulators developed at NASA LaRC.

provides several benefits that have been incorporated into the latest generation, Tendon-Actuated Lightweight InSpace MANipulator (TALISMAN). These benefits include the mechanical advantage provided by the spreaders that offset the tension elements at the joints, reducing the required motor size and providing geometric stiffness in the plane of the spreaders; and the simplicity of the structural design that allows rapid analytical modeling and sizing. TALISMAN, like the LSMS, provides multi-mission capabilities, with applications including asteroid retrieval and 
manipulation, in-space servicing, and astronaut and payload positioning ${ }^{3-5}$. Given this mission versatility, a structural sizing methodology was developed to rapidly assess mass and configuration sensitivities for any specified operational work space, applied loads and mission requirements. This methodology allows the systematic sizing of the three sets of TALISMAN primary structural members (Fig. 1b), which include the truss arm links, the spreaders and the tendons (tension elements). This analysis capability allows TALISMAN designs to be integrated into mission architecture trade studies that are ongoing at NASA and provides the initial design sizing for more detailed dynamics $^{6,7}$ and controls ${ }^{8}$ studies being performed within the TALISMAN research team. This paper details the implementation of the structural sizing methodology in a custom code written in MATLAB, and provides results from a recent design of multiple TALISMANs envisioned for use on the Asteroid Redirect Mission (ARM) Concept B. Derivations of the sizing equations are provided in the Appendix.

\section{Structural Sizing Methodology}

Initially, closed-form, parametric equations were derived for sizing the three primary sets of structural members for TALISMAN and were used in a rapid-design spreadsheet described in Doggett $e t$ al ${ }^{3}$. This spreadsheet-based design tool produced conservative structural mass estimates and sizing for a fully-extended TALISMAN, subject to in-plane tip loads, where the design used the same member geometry for each set of arm links, spreaders and tendons throughout. However, the closed-form equations did not include axial tip loads, and only the maximum resultant loads in each set of primary structural members were used for sizing. Recent mission analyses have required a more comprehensive structural optimization approach that includes the ability to vary individual member lengths; size members based on the individual member loads; include the effects of different manipulator poses; and consider a well-defined and actively-controlled operational envelope to better specify the loading and stiffness requirements. As a result, a new and more sophisticated design tool was created in MATLAB and is being used for sizing and sensitivity analyses that are based on current NASA mission architectures and possible future TALISMAN applications.

The TALISMAN structural geometry that is used in the MATLAB sizing code is shown in Fig. 2. The arm links are truss beams that can be manufactured from water-jetting an off-the-shelf rectangular tube made of metal or

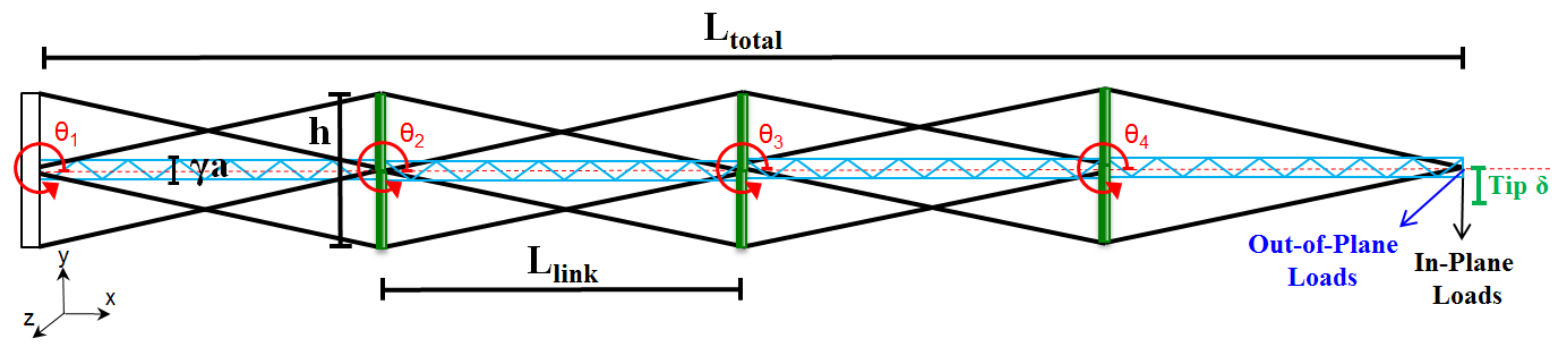

a) TALISMAN geometry, joint angles, tip loads and tip deflection.

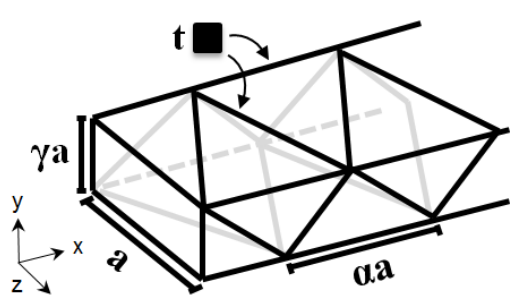

b) Truss beam links.

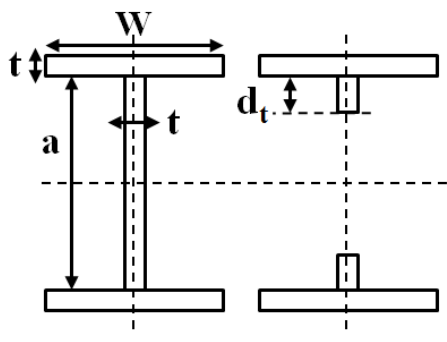

c) Closed and open-section I-beam spreaders.

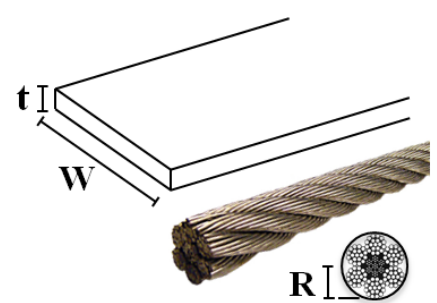

d) Tendons (webbing or cable).

Figure 2. TALISMAN geometry, primary members, loads, and tip displacement definitions.

composite. This results in the wall thickness, t, being the primary sizing parameter for the arm links. The truss link width, a, and link depth, $\gamma$ a, are chosen to closely house the motors, gearbox and electronics inside the truss beam, providing them protection and also enabling the TALISMAN to have a compact packaging scheme while still maximizing the area moments of inertia of the links. A rectangular cross-section is chosen to provide additional out- 
of-plane stiffness, since the global stiffness in that direction is not aided by the spreaders. The truss links have an additional sizing parameter, $\alpha$, that defines the length of the local bays in each link. This parameter changes the angles of the diagonals and allows optimization of the link torsional stiffness that may be required for out-of-plane loads induced when the joint angles, $\theta_{\mathrm{i}}$, are non-zero. The spreaders are the vertical members attached at each joint, and used in conjunction with the tendons, to provide mechanical advantage and in-plane stiffness. I-beams are used for the spreaders to enable compact stowage alongside the arm links. Each spreader is composed of two crosssections; a standard, closed-section I-beam on one side of the link, and an open-section I-beam on the otherside (with a large portion of the central webbing cut out from top to bottom). The open-section side allows the spreader to be unlocked at the joint and driven in the direction of the closed section ${ }^{5}$, providing the ability to dynamically alter the geometry of the TALISMAN for a specific operation, such as increasing the in-plane stiffness on that side. In addition, a more compact packaged state can be achieved by retracting the spreaders. Since the packaging scheme requires a Z-fold of the links, the open- and closed-section sides of the spreaders alternate at each adjacent joint along the length of the TALISMAN to provide the most compact packaging. The spreaders are constrained to the width of the truss links, a, however, the wall thickness, $t$, could be used as a sizing parameter, although it is also partially constrained by the desire to maintain a compact joint. The flange width, $\mathrm{W}$, is therefore used as the sizing parameter, as its magnitude is only restricted by the link depth, ya, on each side. Finally, the tendons are cables in the current, as-built hardware prototypes, but future variants of the TALISMAN may use composite webbings or tapes for their increased stiffness and linearity. The sizing parameter is the cable radius, $R$, but since the sizing is only based on the tensile strength, the sized area can be readily converted to a width and thickness of a candidate webbing for future studies.

\section{A. TALISMAN Sizing Code}

The MATLAB sizing code includes three major sections: (1) define the materials, loads, tip deflection and geometry, i.e. create the TALISMAN model and the pose cases, (2) determine the equilibrated load state that maintains the minimum pretension level in all tendons and achieves the tip deflection requirement, and (3) size the structural members and output the results. A flowchart of the sizing code and its two primary sizing functions are provided in Fig. 3.

In the first section of the code, the material properties are stored in arrays that define the modulus of elasticity, density, and ultimate stress in tension and compression. Safety factors on strength and buckling are defined and a separate, higher safety factor on tendon strength is also designated due to a requirement on tensioned cables in proximity to personnel, such as astronauts performing an extra-vehicular activity (EVA). The primary design inputs (or objectives) are the applied tip loading and stiffness, since these parameters govern the operational capability of the manipulator. The TALISMAN achieves high structural efficiency, in terms of tip force and stiffness, by maintaining the applied loads in the plane of the spreaders through judicious path planning and control. An out-ofplane load is however included in the sizing as a defined percentage of the in-plane load, to provide robustness to small, off-nominal side loads. The minimum desired pretension level and a kick load are also defined. The TALISMAN system considered in this analysis is "active-active", or actively-antagonistic, meaning that motors actively control tendons that oppose each other about a joint. This allows the pretension level to be controlled prior to, and during, external load application. A kick load is required for structures used during EVA to account for incidental contact by an astronaut, and is defined as a $556 \mathrm{~N}(125 \mathrm{lbf})$ impulse load on any exposed part ${ }^{9}$. Adding this load case to a prototype design helps to ensure the structure is robust to typical handling. Finally, in this section, the TALISMAN geometry is defined to include link lengths and cross-sectional dimensions; spreader heights with wall thickness and open-section tab length, $\mathrm{d}_{\mathrm{t}}$; and a matrix of poses, where each row of the matrix is a set of joint angles used in the sizing analysis. The nodal coordinates of the connections between the primary members are calculated in the straight out (zero-joint angle) configuration, and a connectivity matrix is defined to associate the nodal coordinates with each member (graphically shown in Fig. 4a).

In the next section of the code, the joint angles in the model are updated to one of the requested poses and the load analysis is performed. The MATLAB design tool takes advantage of the pinned-truss geometry of the TALISMAN by using the matrix stiffness method to calculate the loads in the system. This method assumes that all primary structural members are axially loaded. Even though there may be a small offset distance on each side of the joint, where the tendons connect to the motor/gearbox, the tendons intersect the link at the same distance along the link providing a net axial compression. The matrix stiffness method constructs the equations of equilibrium and compatibility in matrix form, along with the elemental stiffness matrix, to define the relationships between the external loads, pretensions, nodal displacements and boundary conditions, with the internal member loads and displacements. This computational method can solve statically indeterminate (internally preloaded) structures such as the TALISMAN and is computationally inexpensive. The preloads in the members are included in the model by 
converting them, through the equilibrium matrix, to nodal forces that are added to the external nodal load vector.

TALISMAN Sizing Code

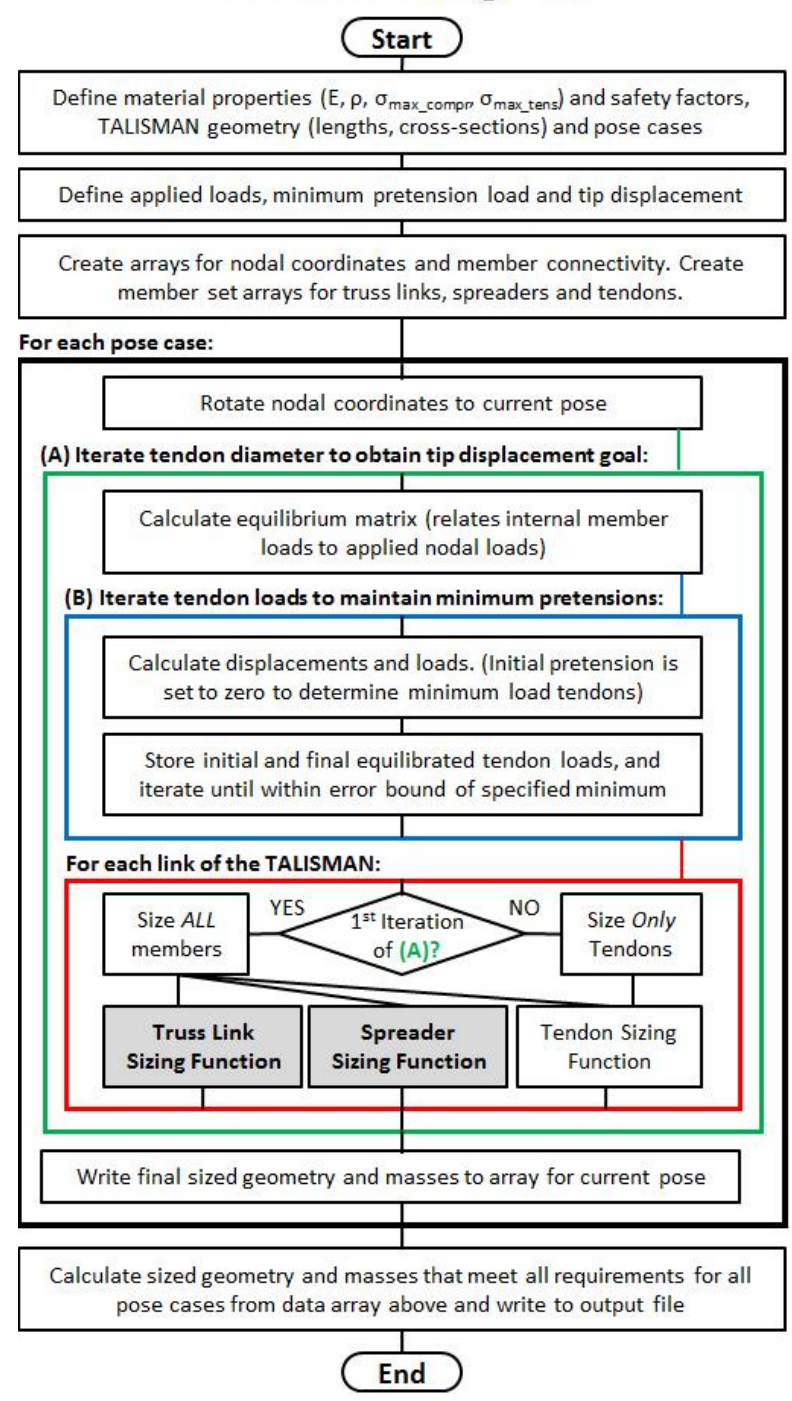

Truss Link Sizing Function

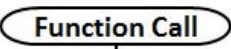

For current TALISMAN link receive INPUTs: truss link forces, applied loads, material properties, safety factors and cross-sectional geometry

Calculate moment arm lengths in bending / torque from lateral tip load

Iterate $\alpha$ (truss link bay length/width ratio):

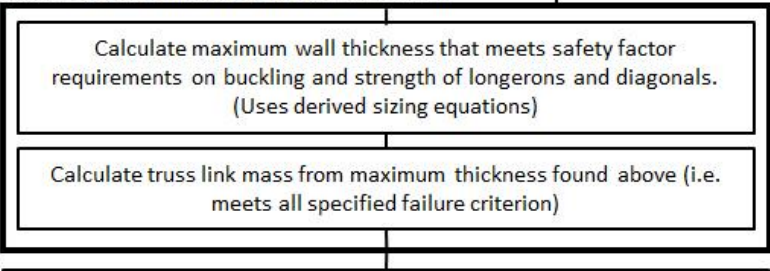

Determine $\alpha$ that produces the minimum mass case and OUTPUT: $\alpha, \mathrm{t}$, mass, A, and driving failure type (i.e. longeron buckling)

Function Return

\section{Spreader Sizing Function}

Function Call

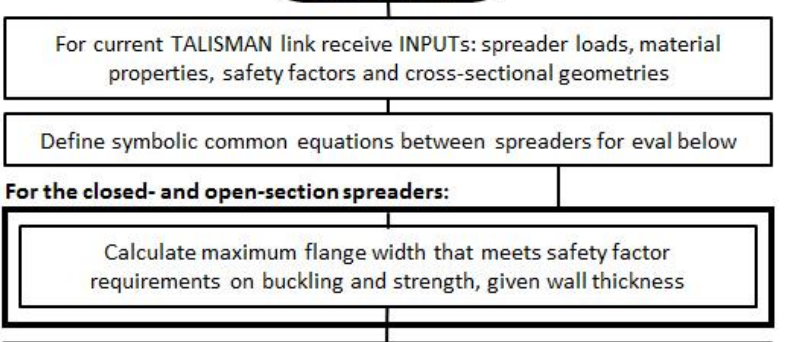

Calculate spreader mass from maximum flange width (i.e. meets all specified failure criterion for BOTH spreaders)

OUTPUT: W, mass, A, and driving failure type (i.e. compressive strength) Function Return

Figure 3. TALISMAN sizing code and function flow charts.

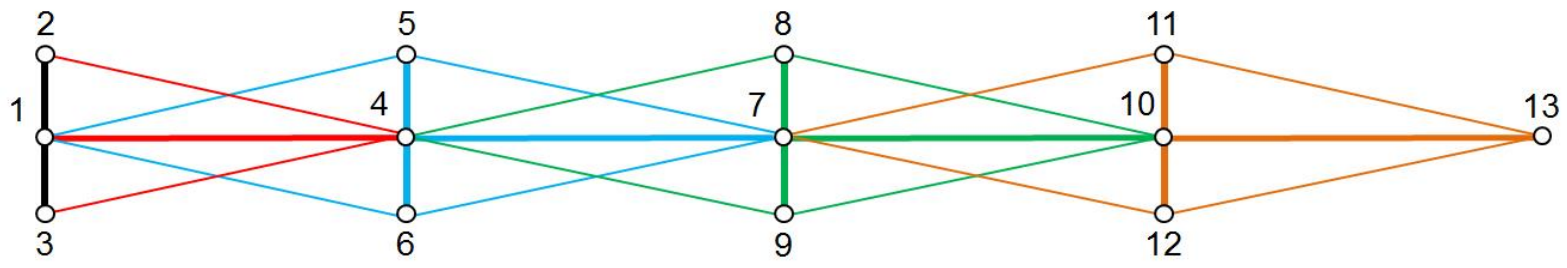

Figure 4. Nodal coordinates and connectivity for a 4-link TALISMAN in a zero joint angle configuration. (Colors represent structural members associated with each of the four links).

Initially, the preloads are set to zero and the member loads are calculated with only external loads applied, which results in some of the tendons going into compression. The tendons with the lowest loads associated with each link (see Fig. 4 for definition of the member groups) are selected as the driving tendons for the pretension iterations, in order to guarantee all tendons will achieve the minimum required preload after equilibrium. The initial pretensions are set equal to the applied tip load in the first pretension iteration, after which they are updated by polynomial curve 
fitting of the initial and resultant preload data from each iteration. Once the model obtains an equilibrated load state, where the minimum tendon load is met, the members are sized (as detailed below) and the tip displacement requirement is checked. If the tip displacement does not meet the requirement, then the tendon radius is scaled in proportion to the current tip displacement and the load and sizing calculations are performed again until the tip displacement requirement is satisfied within a defined error bound.

The sizing section of the code is split into three functions that size the truss links, spreaders and tendons. The derivations of the sizing equations used in these functions are included in the Appendix and a flow chart of the truss link and spreader sizing functions are given in Fig. 3. The tendon sizing function is the simplest, as it only requires checking the ultimate tensile strength to size the radius. However, as detailed in the previous section, iterations are also performed (in the green loop A of Fig. 3) that adjust the radius to meet the global tip stiffness requirement. The truss links are sized primarily by the local members that are produced from water-jetting a rectangular tube. These local members are the longerons and diagonals of the truss link and have square cross-sections of side $t$ (i.e. the wall thickness of the link). The truss link sizing function receives the property data for the current link and its member forces. If an out-of-plane load is specified, the bending and torsional moments, produced at the root of the link, are calculated and included in the resultant loads for sizing. Buckling and strength equations are formulated for the longerons and diagonals (Appendix) and the maximum wall thickness, $t$, is calculated along with the resulting truss link mass. These equations are executed within an iterative loop that searches for the $\alpha$ (local truss bay length / width ratio, Fig. 2) that produces the lowest link mass. The final values of $t, \alpha$, cross-section area, mass and the sizing failure criterion are returned to the main code. The spreader sizing function also receives the properties and member loads, but is unaffected by any out-of-plane tip load for these initial sizing assumptions due to its location at the joint. In theory, a large moment at the tip could impact the spreader locally, but the joint and links are likely to fail first under such loading. Buckling and strength criteria are defined, for both the open- and closed-sections of the spreader (Appendix) and the flange width, W, is sized for both sections. Since the spreader is a continuous member, the maximum value of $\mathrm{W}$, from both sides, is selected and used to calculate the spreader mass. The final values of $\mathrm{W}$, cross-section area, mass and the sizing failure criterion are then returned to the main code.

Sizing of the truss links and spreaders is only performed in the first iteration of the outer, tip displacement loop (loop A in Fig. 3). This might seem counter-intuitive for a statically indeterminate structure, where a change in the stiffness of the tendons could alter the loads, and hence the required sizing of the other members. However, due to the pretension level being set in each iteration, and the applied loads remaining constant, the member loads also remain constant throughout this loop. For each TALISMAN pose case, a data array is produced that stores geometric, mass, and failure criterion data. After all pose cases are processed, the maximum member sizes are selected from all analyzed cases and are output as the final design sizing from the code. This design meets all load and displacement requirements across all pose cases.

\section{B. TALISMAN Geometry / Link Sizing Code for ARM}

The MATLAB sizing code described in Section II. A, takes the initial geometry of the links and spreaders as an input. For a given TALISMAN design, the number and length of the links are chosen to provide both a desired reach and operational workspace, i.e. dexterity within the reach envelope. Packaged volume may also be important for a particular mission, thus more shorter links may be advantageous over fewer, longer links. The most recent design study for which TALISMAN sizing was performed was for the Asteroid Redirect Mission (ARM) Concept $\mathrm{B}^{4}$. This mission architecture employed three TALISMANs as grapple arms to pick up a boulder on the surface of a $100 \mathrm{~m}$ class asteroid, and three additional TALISMANs as landing legs to enable a soft touchdown on, and push-off from, the asteroid. This mission architecture added a further series of constraints on the TALISMAN geometry and workspace by requiring obstacle avoidance around the spacecraft, the boulder, and the surface of the asteroid. To expedite the selection of link and spreader lengths for ARM-like architectures, an additional MATLAB code was written to investigate and size the TALISMAN geometry required for grapple and landing operations. This code, to define and plot the geometry, and its core joint angle configuration function is described by the flow charts in Fig. 5 .

The TALISMAN ARM geometry code requires the user to input the dimensions of the Asteroid Retrieval Vehicle (ARV) to which the TALISMAN grapple arms and landing legs are attached around the ARV hexagonal baseplate. The boulder is defined as an ellipsoid, with principle axes (diameters) of lengths $\mathrm{D}_{1}, \mathrm{D}_{2}$, and $\mathrm{D}_{3}$. Additional inputs include the current distance between the ARV baseplate and the asteroid surface (Fig. 6); the buried depth of the boulder; the minimum clearance distance between the TALISMAN spreaders and the boulder; and the tip contact point on the boulder for the grapple arms or on the surface for the landing legs. The three grapple arms and three landing legs are run as two separate sizing cases. For the grapple arm case, each of the three TALISMANs may have a unique set of joint angles if the radius (semi-major axis of the elliptical surface path) of the tip contact point on the boulder is different for each, which depends on the dimensions of the boulder ellipsoid. 
TALISMAN ARM Geometry Code

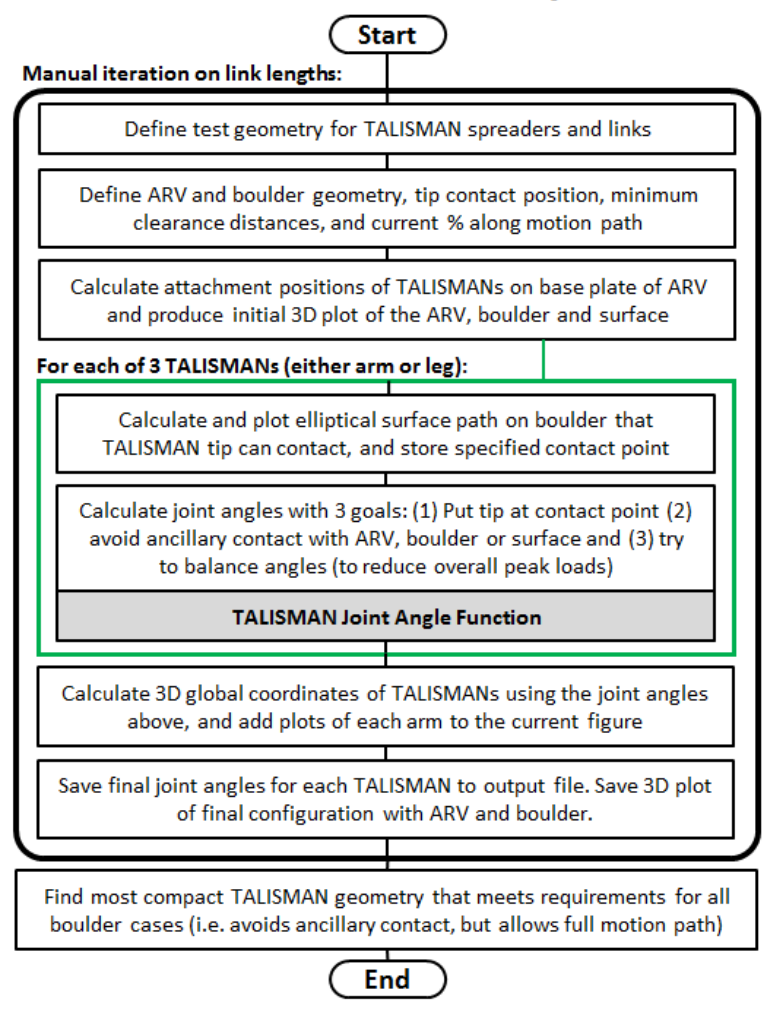

TALISMAN Joint Angle Function

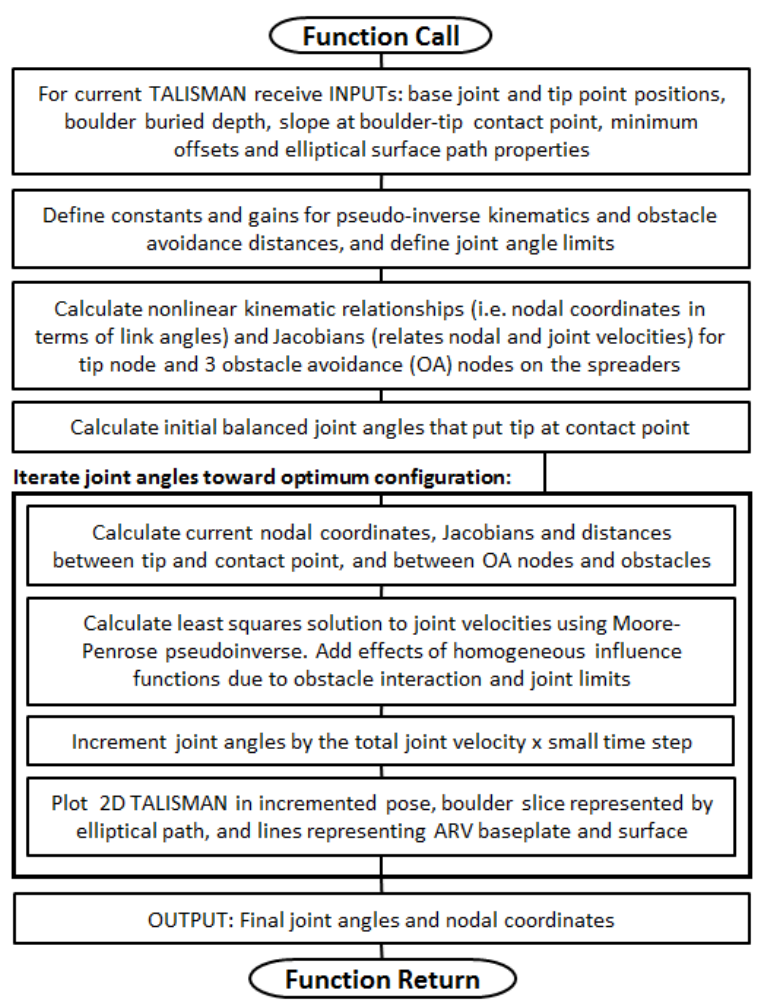

Figure 5. TALISMAN geometry code and joint angle function flow charts.
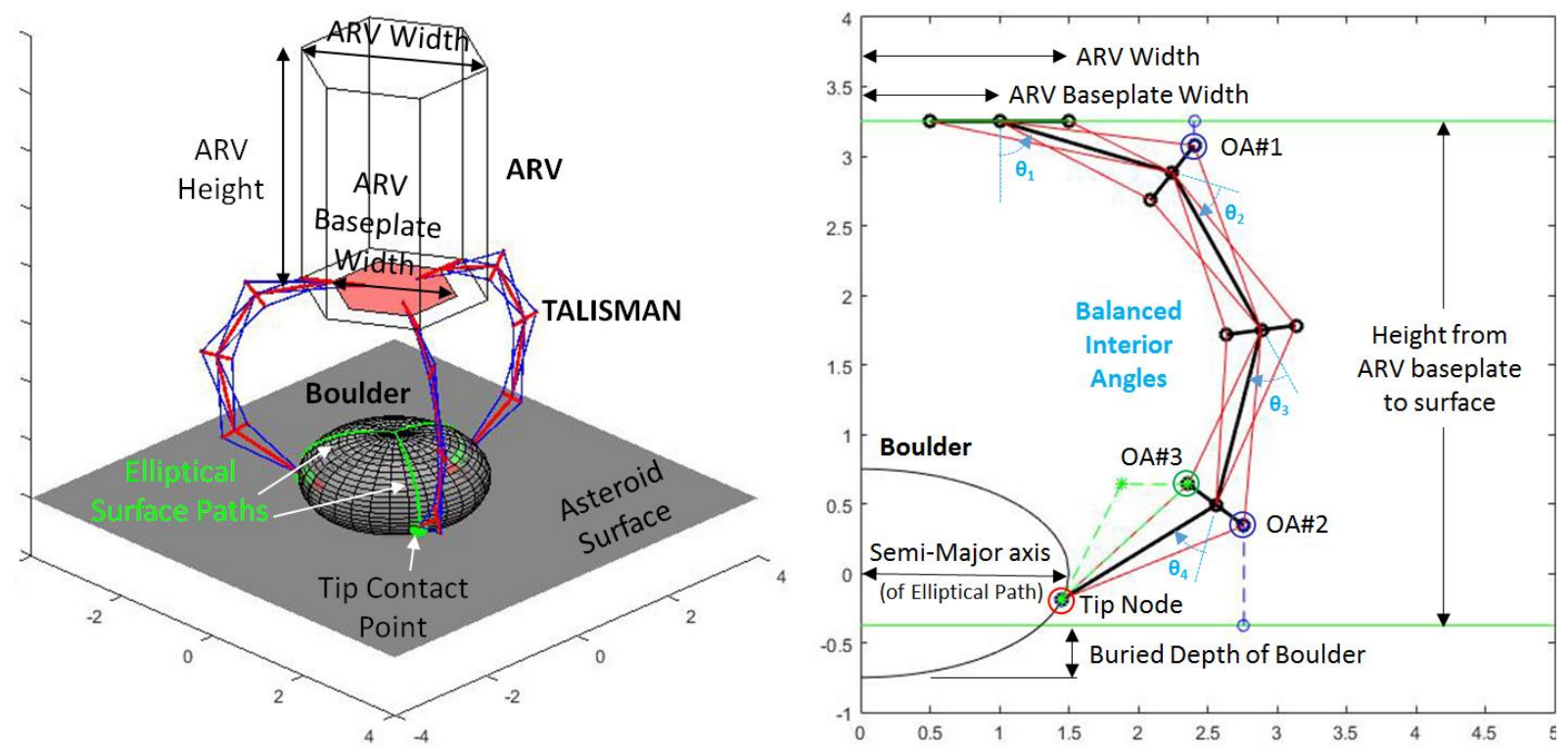

Figure 6. TALISMAN grapple arm geometry with key features and nodes highlighted.

As all three grapple arms have to perform a coordinated grapple and retraction (or for the landing legs, an extension and push-off), the tips of the TALISMANs in both cases trace a vertical path. Therefore, a final parameter defines the tip location along that vertical motion path, as a percentage of the total distance it travels in each case, simplifying the definition of the tip contact point for the user. Initial link and spreader lengths are defined and the 
ARV, boulder and surface plane are plotted in three-dimensions (3-D). Each of the three TALISMANs, for a given mission design analysis, are equally spaced at 120 degrees around the base of the ARV. The grapple arms and landing legs are adjacent to each other, 60 degrees apart. The actuation plane of each grapple arm is aligned with an elliptical slice through the boulder. This elliptical surface path defines the set of viable grapple arm tip contact points and is added to the 3-D plot for each arm. This ellipse is also used in the joint angle configuration function to define the two-dimensional (2-D) shape of the boulder.

The joint angle function is called for each of the three TALISMANs in a set (either grapple arms or landing legs) and includes the following inputs: the elliptical surface definition, the base node and tip contact coordinates, the boulder buried depth, the slope at the boulder-tip contact point (for the grapple arms) and the minimum clearance distance. This function was primarily written to adjust the joint angles of the grapple arms while following three objectives: 1) place the tip at the desired contact point on the boulder; 2) avoid ancillary contact between the TALISMAN and the ARV, boulder or surface; and 3) try to balance the joint angles to reduce the peak magnitude of any one angle (i.e. eliminate kinks) and thus reduce peak loads in the TALISMAN. An example of a grapple arm with balanced joint angles is shown in Fig. 6. Currently, a pseudoinverse kinematics approach is being explored to iterate the joint angles, while also implementing forcing functions for obstacle avoidance and joint angle balancing, as described in the robotics literature ${ }^{10,11}$. The pseudoinverse, $\mathrm{J}^{+}$, is a generalized inverse of the Jacobian, $\mathrm{J}$, for transforming nodal velocities, $\dot{X}$, into joint velocities, $\dot{\theta}$, in manipulators with redundant degrees of freedom. From reference 10 , where $I$ is the identity matrix and $z$ is an arbitrary vector of joint velocities:

$$
\dot{\theta}=J^{+} \dot{X}+\left(I-J^{+} J\right) z
$$

The first part of Eq. 1 is the least squares solution to the redundant system of equations, and the second part is a homogeneous solution that operates in the null space of the transformation. $z$ can be produced by a forcing function and projected, via the term in parentheses, into the null space. Several forcing terms can be included in this manner that influence the joint angle iterations without hindering the primary goal of directing the tip to the desired contact point. The obstacle avoidance (OA) forcing terms are written for three OA nodes (shown in Fig. 6) that make the closest approaches to the ARV, boulder and asteroid surface. An OA term is only activated once the OA node comes within a defined sphere of influence (SOI) of the obstacle with which the OA node is associated. The gain of the OA term is then ramped up quadratically as the node approaches the obstacle until a maximum gain is reached at a prescribed distance. These distances and gains can be varied in the code to adjust their influence on the joint angle iterations. Soft joint limits are also prescribed, using a fourth forcing term that acts in a similar manner to the OA terms, ramping quadratically to a maximum gain at the joint limits around a defined optimal angle. These limits are classified as 'soft' as there is not a hard cutoff of the analysis at the joint limits, instead the specified maximum gain would be exceeded. The optimal angles are defined as the set of balanced interior angles (Fig. 6) that place the tip at the desired contact point given a fixed base point. If the obstacle constraints are met in this initial, balanced angle configuration then no iteration is needed. If an obstacle constraint is violated then iterations are performed to progress towards a more optimal joint angle solution. It is also possible that no solution exists, if the original link or spreader dimensions were poorly chosen for the current boulder geometry. At each stage of the iteration cycle, a plot like that shown on the right side of Fig. 6 is produced to display the progress of the optimization to the user. Once a final set of joint angles are obtained, the angles and nodal coordinates are returned to the main geometry code.

The function is repeated for the other two TALISMANs and the final configurations are plotted in the original 3-D figure. The configuration results are stored to an output data file that can be referenced in the TALISMAN sizing code as pose input data. When performing configuration analyses in which multiple different sized boulders are to be retrievable by the capture system of grapple arms and landing legs, it is likely, that the initially chosen link and spreader lengths will have to be updated and additional runs of the program performed to obtain a final geometry for the arms and legs that satisfy all boulder cases (outer loop of TALISMAN ARM geometry code, Fig. 5). The following section discusses results from a recent case study for the ARM Concept B that utilizes both codes described in Section II to size sets of grapple arms and landing legs with the capability to retrieve a wide range of different boulder sizes from an asteroid.

\section{Results from ARM Concept B Mission Sizing for asteroid 2008 EV5}

The ARM Concept B was selected in March 2015 as the focus for ongoing studies into a boulder retrieval and return mission with a possible launch in late 2020. Several candidate $400 \mathrm{~m}+$ diameter carbonaceous asteroids have been identified as possible targets for such a mission including: Bennu, currently the target of the OSIRIS-Rex 
sample return mission; $1999 \mathrm{JU}_{3}$, the target of the Japanese Hayabusa 2 sample return mission; and 2008 EV5. 2008 EV5 is currently preferred in the NASA ARM Concept B studies ${ }^{12}$ due to EV5 having been extensively observed and characterized from ground-based infrared telescopes and radars (Fig. 7). The MATLAB codes described in

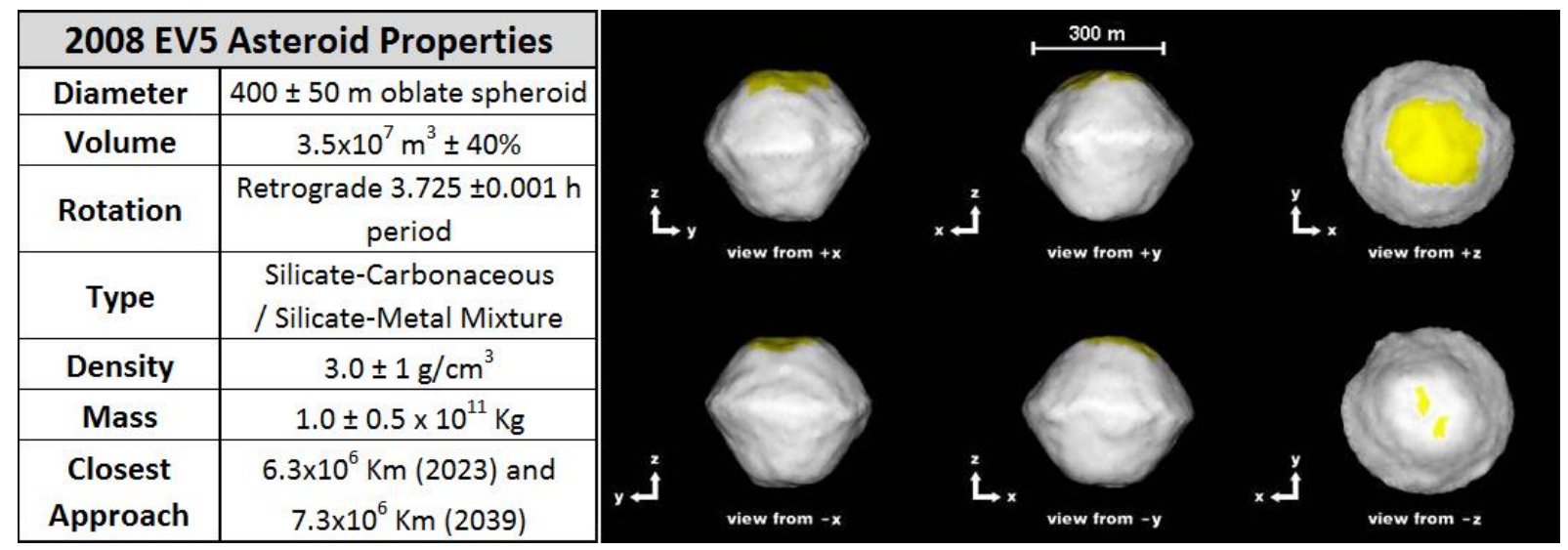

Figure 7. 2008 EV5 properties $^{13,14}$ and radar shape model from Ref. 14.

Section II were used to size three TALISMAN grapple arms and three TALISMAN landing legs for a conceptual boulder retrieval mission to 2008 EV5. The key stages of the capture operation are shown in Fig. 8 for a previously studied boulder retrieval mission to Phobos, using the same TALISMAN-based capture architecture. The current baseline operations for the capture portion of the EV5 mission begin with the ARV at zero relative velocity to the surface, $20 \mathrm{~m}$ above the center of the boulder. The ARV then uses the low gravity of EV5 to pull itself towards the surface at a very slowly increasing velocity until the landing legs make contact. The landing legs then lower the ARV toward the surface until the grapple arms can secure the boulder at three points. The grapple arms then retract the boulder and secure it against the ARV, after which the landing legs push the ARV off the surface, reaching a maximum velocity that, at a minimum, propels the ARV to a height of $50 \mathrm{~m}$ above the surface.

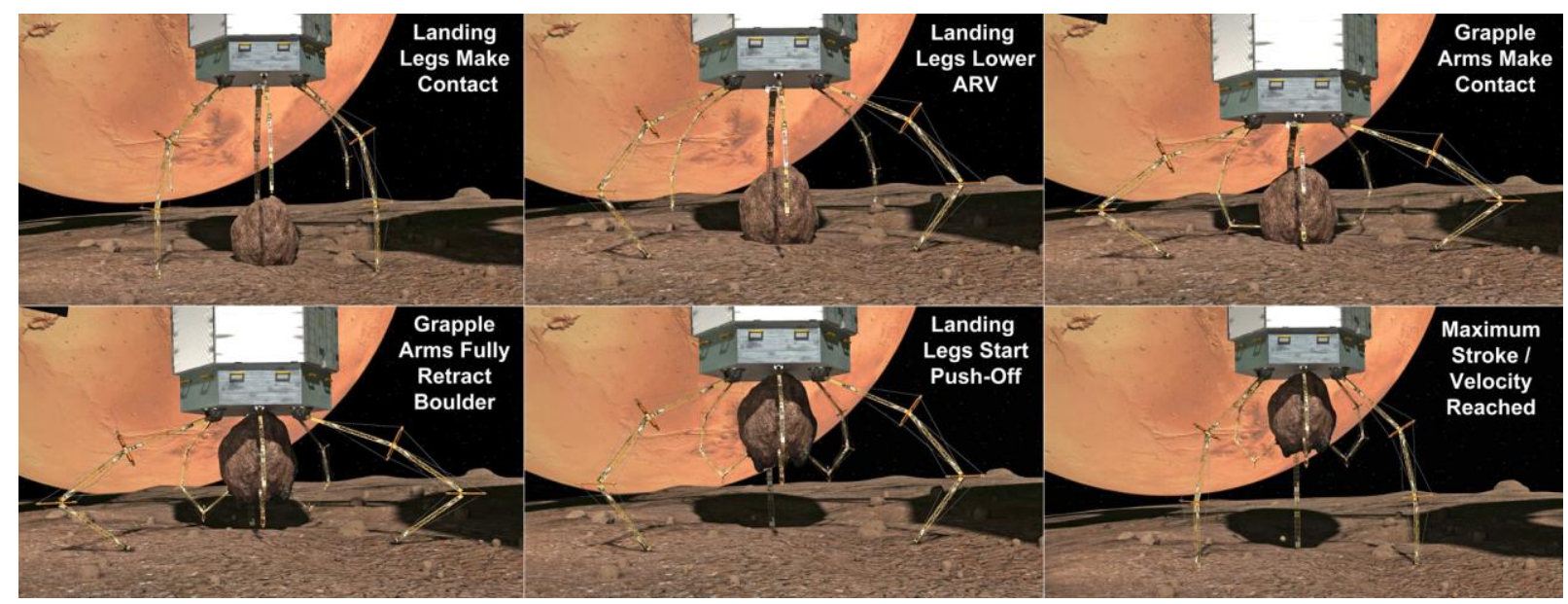

Figure 8. Artist's concept of TALISMANs used as landing legs and grapple arms for a Phobos boulder retrieval mission.

\section{A. TALISMAN Geometry and Configuration}

The ARM mission Concept $\mathrm{B}$ is focused on retrieving one boulder, $1 \mathrm{~m}$ to $5 \mathrm{~m}$ in diameter, with a maximum mass of 70,000 Kg (70 metric tons [MT]) from the surface of $2008 \mathrm{EV} 5$. The LaRC ARM study team defined ten ellipsoid boulder geometries for study that encompassed a wide range of sizes (Fig. 9). These shapes provide a baseline set of analysis cases that any capture system must be able to grapple and secure, and assist in the push-off of the spacecraft and boulder from the asteroid surface. From a geometric sizing perspective, the links of the grapple 
manipulators must be able to reach around any of the boulders and maintain tip contact throughout the grapple and secure maneuver while avoiding any ancillary contact with the boulder, surface or ARV. The landing leg geometries are not as constrained by the boulder geometry, but they must provide enough force and vertical stroke to launch the

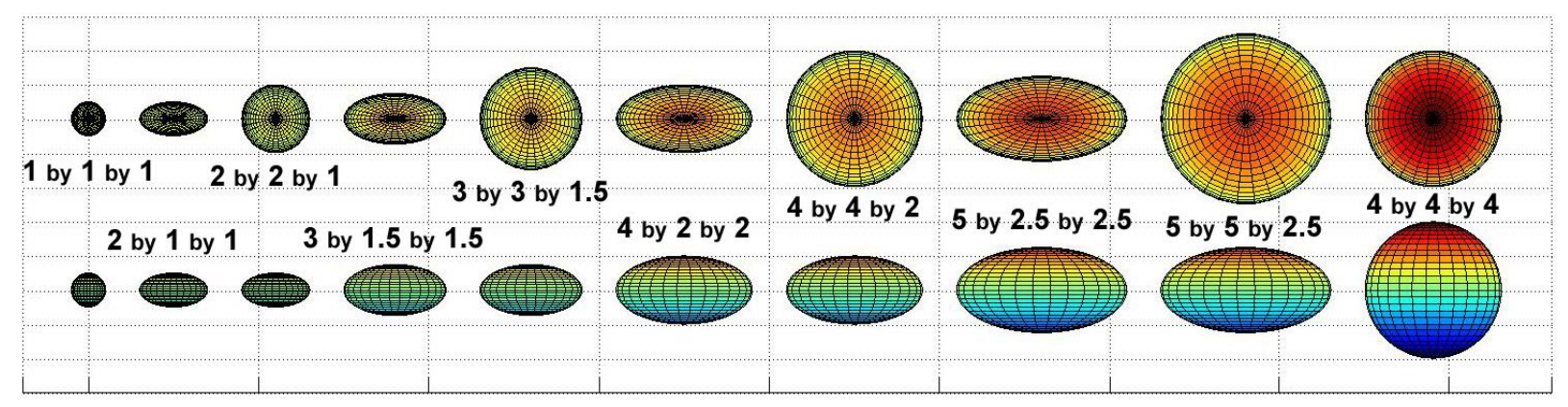

Figure 9. Boulder geometry cases for ARM Concept B (dimensions in meters).

full mass of the ARV and boulder to at least a height of $50 \mathrm{~m}$ above the surface. The launch height is stipulated in the mission architecture to avoid having to use thrusters near the surface of the asteroid, which could cause damaging dust particles to be ejected toward the spacecraft and solar arrays. A push-off stroke of $1 \mathrm{~m}$ was chosen for the landing legs as a reasonable estimate (given the low gravity environment) over which to accelerate the ARV and boulder to a velocity that could achieve the required $50 \mathrm{~m}$ height.

The boulder cases that drove the sizing were found to be the smallest boulder ( $1 \mathrm{~m}$ by $1 \mathrm{~m}$ by $1 \mathrm{~m})$, and the two largest boulders ( $5 \mathrm{~m}$ by $5 \mathrm{~m}$ by $2.5 \mathrm{~m}$ and $4 \mathrm{~m}$ by $4 \mathrm{~m}$ by $4 \mathrm{~m}$ ). These three cases are all axisymmetric about the vertical axis and thus only one set of poses was required for each set of grapple arms and landing legs. The mass of the $1 \mathrm{~m}$ by $1 \mathrm{~m}$ by $1 \mathrm{~m}$ boulder is only $1 \mathrm{MT}$ to $2 \mathrm{MT}$, but due to the requirement of using the same manipulator geometry for all ten boulder sizes, retracting such a small boulder leads to a larger range of motion and more severe joint angles which must be checked. For the two largest boulders (cases 9 and 10 in Table 1), the manipulators are geometrically sized to achieve minimum clearances. The range in density of 2008 EV5 allows for a factor of 2 difference in mass for any given boulder volume. Due to the maximum payload limit of 70 MT for this mission, the only way the two largest boulders could be retrieved would be if their densities were at most, approximately 2 $\mathrm{g} / \mathrm{cm}^{3}$. For boulder cases 1 to 8 , the density is assumed to be $4 \mathrm{~g} / \mathrm{cm}^{3}$ to be conservative.

Table 1. Boulder dimensions and masses for 2008 EV5 expected density range.

\begin{tabular}{|c|c|c|c|c|c|c|c|c|}
\hline CASE & D1 & D2 & D3 & Volume & Density & Mass & Density & Mass \\
\hline$\#$ & (m) & (m) & (m) & $\left(\mathrm{m}^{3}\right)$ & $\left(\mathrm{g} / \mathrm{cm}^{3}\right)$ & $(\mathbf{K g})$ & $\left(\mathrm{kg} / \mathrm{m}^{3}\right)$ & $(\mathrm{Kg})$ \\
\hline 1 & 1 & 1 & 1 & 0.52 & 2 & 1047 & 4 & 2094 \\
\hline 2 & 2 & 1 & 1 & 1.05 & 2 & 2094 & 4 & 4189 \\
\hline 3 & 2 & 2 & 1 & 2.09 & 2 & 4189 & 4 & 8378 \\
\hline 4 & 3 & 1.5 & 1.5 & 3.53 & 2 & 7069 & 4 & 14137 \\
\hline 5 & 3 & 3 & 1.5 & 7.07 & 2 & 14137 & 4 & 28274 \\
\hline 6 & 4 & 2 & 2 & 8.38 & 2 & 16755 & 4 & 33510 \\
\hline 7 & 4 & 4 & 2 & 16.76 & 2 & 33510 & 4 & 67021 \\
\hline 8 & 5 & 2.5 & 2.5 & 16.36 & 2 & 32725 & 4 & 65450 \\
\hline 9 & 5 & 5 & 2.5 & 32.72 & 2 & 65450 & 2.14 & 70000 \\
\hline 10 & 4 & 4 & 4 & 33.51 & 2 & 67021 & 2.09 & 70000 \\
\hline
\end{tabular}

The final sized link lengths for the grapple arms and landing legs, that met all constraints and boulder cases, were determined to be $1.3 \mathrm{~m}$ and $1.6 \mathrm{~m}$, respectively. 4-Link TALISMANs were used for both the grapple arms and landing legs to provide greater dexterity for orienting the tip while performing the operations described. Although a 3-link landing leg configuration was considered, and could provide the necessary motion paths for the EV5 mission, the 4-link design was selected because it provides tighter packaging around the base of the ARV alongside the grapple arms, and some degree of operational redundancy since the design loads on both the arms and legs are very similar for this mission. The spreader lengths for both sets of TALISMANs were $0.25 \mathrm{~m}$ on each side of the link ( $0.5 \mathrm{~m}$ total height). At the root link, the tendons are connected directly to the ARV (nodes 2 and 3 in Fig.4) in place 
of spreaders. As the ARV hexagonal baseplate (to which all the TALISMANs connect) is $2 \mathrm{~m}$ in diameter, and the $\mathrm{ARV}$ is $3 \mathrm{~m}$ in diameter, the connections are placed at the maximum distance of $0.5 \mathrm{~m}$ on each side of the root link. It would also be possible to use telescoping spreaders at the root to provide greater mechanical advantage, but since the final structural masses for the EV5 mission were relatively small, this approach was unnecessary. The pose cases determined for the structural sizing are shown in Table 2, with Fig. 10 illustrating the pose cases studied for the $5 \mathrm{~m}$

Table 2. 2008 EV5 TALISMAN landing leg and grapple arm pose cases and sized dimensions.

\begin{tabular}{|c|c|c|c|c|c|}
\hline \multicolumn{6}{|c|}{ Landing Leg Pose Cases for Sizing } \\
\hline $\begin{array}{l}\text { Push-Off } \\
\text { (m) }\end{array}$ & $\begin{array}{c}\text { Boulder } \\
(\mathrm{m} \text { by } \mathrm{m} \text { by } \mathrm{m})\end{array}$ & $\begin{array}{c}\theta_{1} \\
\text { (Degs) }\end{array}$ & $\begin{array}{c}\theta_{2} \\
(\text { Degs) }\end{array}$ & $\begin{array}{c}\theta_{3} \\
\text { (Degs) }\end{array}$ & $\begin{array}{c}\theta_{4} \\
(\text { Degs })\end{array}$ \\
\hline 0 & 4 by 4 by 4 & 77.12 & -34.64 & -37.14 & -37.14 \\
\hline 0.5 & 4 by 4 by 4 & 62.12 & -22.64 & -30.64 & -36.14 \\
\hline 1 & 4 by 4 by 4 & 61.12 & -43.64 & -15.64 & -1.64 \\
\hline 0 & 5 by 5 by 2.5 & 77.12 & -5.29 & -57.79 & -82.29 \\
\hline 0.5 & 5 by 5 by 2.5 & 80.12 & -17.29 & -52.04 & -66.04 \\
\hline 1 & 5 by 5 by 2.5 & 79.12 & -24.29 & -48.29 & -48.79 \\
\hline \multicolumn{6}{|c|}{ Landing Leg Dimensions } \\
\hline \multicolumn{6}{|c|}{$\begin{array}{l}\text { Links: } 1.6 \mathrm{~m} . \text { Cross-section, wxh: } 76 \text { by } 38 \mathrm{~mm}\left(3^{\prime \prime} \text { by } 1.5^{\prime \prime} \mathrm{in} .\right) \\
\text { Spreaders: } 1 \mathrm{~m} \text { at the root / } 0.5 \mathrm{~m} \text { all others (Total } \mathrm{h} \text { ) }\end{array}$} \\
\hline Tendon $\mathbf{R}$ & $\begin{array}{r}\text { Cross-secti } \\
\text { by link: } 5.2,2.1 \\
(0.20,0\end{array}$ & $\begin{array}{l}\text { n I-Bean } \\
2.3,2.9 \\
08,0.09 \text {, }\end{array}$ & $\begin{array}{l}76 \text { by } 25 \\
m \\
11 \text { in.) }\end{array}$ & m (3" $x$ & ' in.) \\
\hline
\end{tabular}

\begin{tabular}{|c|c|c|c|c|}
\hline \multicolumn{5}{|c|}{ Grapple Arm Pose Cases for Sizing } \\
\hline $\begin{array}{c}\text { Boulder } \\
\text { (m by } \mathrm{m} \text { by } \mathrm{m} \text { ) }\end{array}$ & $\begin{array}{c}\boldsymbol{\theta}_{1} \\
\text { (Degs) }\end{array}$ & $\begin{array}{c}\boldsymbol{\theta}_{2} \\
\text { (Degs) }\end{array}$ & $\begin{array}{c}\boldsymbol{\theta}_{3} \\
\text { (Degs) }\end{array}$ & $\begin{array}{c}\theta_{4} \\
\text { (Degs) }\end{array}$ \\
\hline 1 by 1 by 1 & 78.11 & -71.55 & -68.80 & -80.55 \\
\hline 4 by 4 by 4 & 77.11 & -32.48 & -46.23 & -66.73 \\
5 by 5 by 2.5 & 77.11 & -12.80 & -51.80 & -105.80 \\
\hline \multicolumn{5}{|c|}{ Grapple Arm Dimensions } \\
\hline Links: $1.3 \mathrm{~m} . \quad$ Cross-section, wxh: 76 by $38 \mathrm{~mm} \mathrm{(3"} \mathrm{by} \mathrm{1.5"} \mathrm{in.)}$ \\
Spreaders: 1 m at the root / 0.5 m all others (Total h) \\
Cross-section I-Beam: 76 by $25 \mathrm{~mm}$ (3" by 1" in.) \\
Tendon R by link: 3.8, 3.4, 3.5, 2.9 mm \\
(0.20, 0.08, 0.09, 0.11 in.) \\
\hline
\end{tabular}
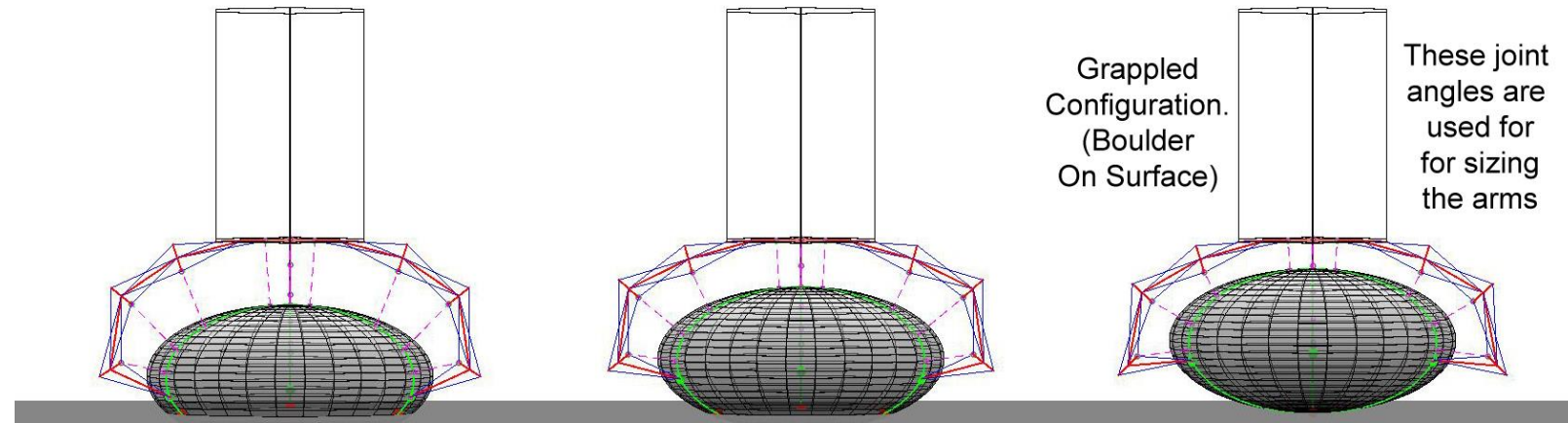

a) Grapple Arms lifting partially buried boulder to secured position against ARV.

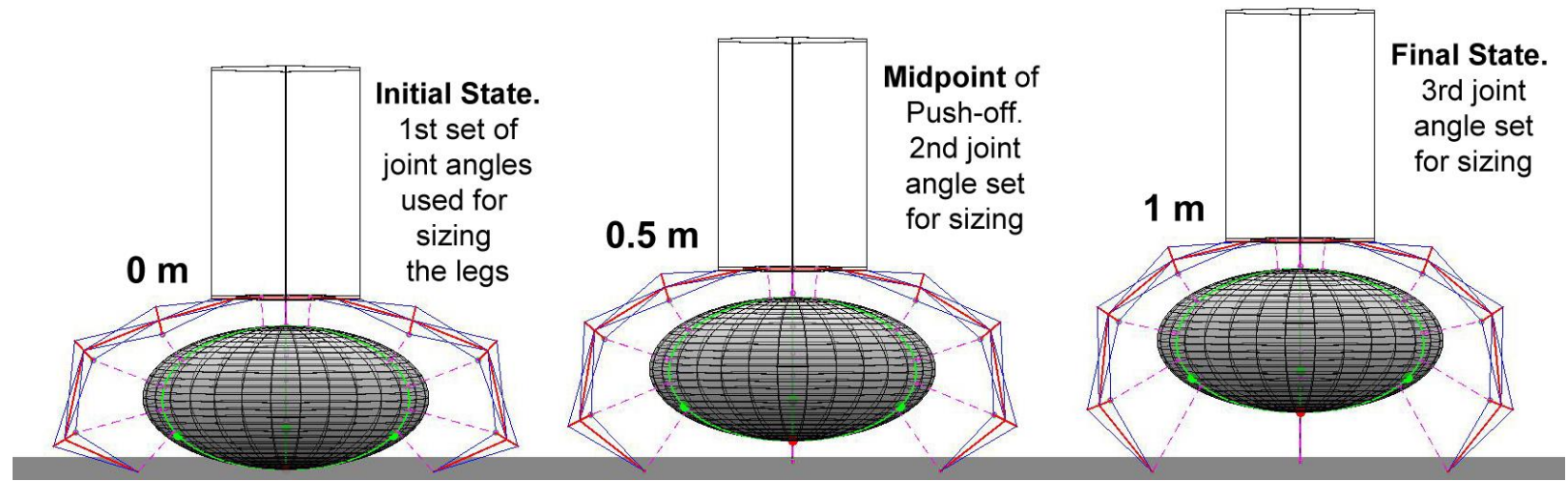

b) Landing Legs pushing ARV off the surface to escape velocity.

Figure 10. Grapple arm and landing leg positions for the $5 \mathrm{~m}$ by $5 \mathrm{~m}$ by $2.5 \mathrm{~m}$ boulder case. Dashed lines represent the geometry code tracking the minimum clearance distances to the spreaders.

by $5 \mathrm{~m}$ by $2.5 \mathrm{~m}$ boulder, as an example. The landing legs react the full inertial load throughout the push-off maneuver, as they accelerate the ARV and boulder; therefore the legs have to be sized to meet the design 
requirements throughout their motion path. Three points along the landing leg motion path for each boulder were selected for sizing, at $0 \mathrm{~m}$ (boulder is on the surface), $0.5 \mathrm{~m}$, and $1 \mathrm{~m}$ (full acceleration has been reached). The $4 \mathrm{~m}$ by $4 \mathrm{~m}$ by $4 \mathrm{~m}$ and $5 \mathrm{~m}$ by $5 \mathrm{~m}$ by $2.5 \mathrm{~m}, 70$ MT boulders generated the peak load and geometric sizing cases. It was determined to be feasible, given the low gravity of EV5, to design the legs to propel the ARV and boulder to escape velocity. As a result, given the total mass of the ARV and boulder $(79,000 \mathrm{Kg})$, the escape velocity on EV5 $(0.26 \mathrm{~m} / \mathrm{s})$, and the $1-\mathrm{m}$ stroke distance, the inertial load on each landing leg at launch is calculated to be $921 \mathrm{~N}$ (207 lbf). The peak load for the grapple arms occurs after the ARV has returned to cis-lunar space ${ }^{12}$ during the final docking maneuver, thus only the fully retracted pose is structurally sized for each of the three critical boulder cases mentioned previously. The docking load on each arm is $885 \mathrm{~N}$ (199 lbf).

The structural sizing code is run using the link and spreader lengths, together with pose cases determined in the geometry sizing code, and a final sizing and mass estimate for each TALISMAN is returned (Table 3). The link cross-sectional dimensions of $76 \mathrm{~mm}$ by $38 \mathrm{~mm}$ ( 3 in. by $1.5 \mathrm{in}$.) used here were chosen based on the volume needed for the internal systems, such as motors, gearboxes and electronics for these smaller manipulators. The tendon radii, particularly at the roots of these TALISMANs, are quite large in this sizing due to the highly conservative requirement of $1 \%$ tip deflection (which has been used in previous TALISMAN sizing studies). The TALISMAN team is currently studying the flexible multibody dynamics ${ }^{6,7}$ and the means to control $^{8}$ this class of manipulators which could reduce the conservative static stiffness requirements currently imposed during design sizing, and decrease the radii of the tendons. The total masses for a single grapple arm and landing leg are given in Table 3, where the quantity and total mass of each set of components is given. The structural mass for an entire arm or leg for

Table 3. 2008 EV5 TALISMAN landing leg and grapple arm component masses.

\begin{tabular}{|c|c|c|c|c|c|c|c|}
\hline \multirow{2}{*}{\multicolumn{2}{|c|}{$\begin{array}{c}\text { MASS TABLE FOR A SINGLE } \\
\text { TALISMAN LEG AND ARM }\end{array}$}} & \multicolumn{6}{|c|}{2008 EV5 Mission } \\
\hline & & \multicolumn{3}{|c|}{ 4-Link Leg } & \multicolumn{3}{|c|}{ 4-Link Arm } \\
\hline Component & Sub-Comp & $(\mathrm{Kg})$ & (lbs) & Qty & $(\mathrm{Kg})$ & (lbs) & Qty \\
\hline & \# of LINKS --> & $\sim$ & $\sim$ & 4 & $\sim$ & $\sim$ & 4 \\
\hline \multirow[t]{4}{*}{ Structure } & Truss Arms & 2.41 & 5.32 & 4 & 1.97 & 4.35 & 4 \\
\hline & Spreaders & 1.45 & 3.19 & 4 & 1.45 & 3.19 & 4 \\
\hline & Cables & 1.07 & 2.35 & 3.5 & 1.08 & 2.38 & 3.5 \\
\hline & TOTAL STRUCTURE: & 4.93 & 10.86 & & 4.50 & 9.92 & \\
\hline \multirow[t]{2}{*}{ Joints } & Arm Hinges & 0.90 & 1.98 & 3 & 0.90 & 1.98 & 3 \\
\hline & Base Rotary & 0.99 & 2.19 & 1 & 0.99 & 2.19 & 1 \\
\hline $\begin{array}{l}\text { Take-up Springs + } \\
\text { Pulley \& Mount Sys }\end{array}$ & $\sim$ & 2.39 & 5.28 & 4 & 2.39 & 5.28 & 4 \\
\hline Motors & $\sim$ & 5.31 & 11.70 & 14 & 4.31 & 9.51 & 14 \\
\hline Gearbox & $\sim$ & 2.87 & 6.32 & 7 & 2.33 & 5.14 & 7 \\
\hline Control Boxes & $\sim$ & 0.54 & 1.19 & 31 & 0.54 & 1.19 & 31 \\
\hline Wiring and Cables & All Wiring & 2.02 & 4.45 & $\sim$ & 1.64 & 3.61 & $\sim$ \\
\hline \multirow[t]{2}{*}{ Sensors } & 4-angle per joint & 0.44 & 0.98 & 13 & 0.44 & 0.98 & 13 \\
\hline & 1-tension per joint & 0.26 & 0.58 & 4 & 0.26 & 0.58 & 4 \\
\hline Cameras & Hardened & 0.66 & 1.46 & 2 & 0.66 & 1.46 & 2 \\
\hline \multirow[t]{2}{*}{$\begin{array}{c}\text { Robotic End Effector, } \\
\text { Pad, or Gripper }\end{array}$} & $\begin{array}{l}\text { Depends on } \\
\text { Application }\end{array}$ & 1.13 & 2.50 & 1 & 1.13 & 2.50 & 1 \\
\hline & TOTAL OTHER: & 17.52 & 38.62 & & 15.61 & 34.41 & \\
\hline SUBTOTAL & & 22.44 & 49.48 & & 20.11 & 44.33 & \\
\hline Growth Factor & $30 \%$ & 6.73 & 14.84 & & 6.03 & 13.30 & \\
\hline TOTAL: & & 29.18 & 64.33 & & 26.14 & 57.63 & \\
\hline
\end{tabular}

this mission is approximately $4.5 \mathrm{Kg}(10 \mathrm{lbs})$ using current polymeric composite materials. The system mass for each TALISMAN is based on known masses of commercial off-the-shelf (COTS) components that are being used in the two laboratory prototypes shown in Fig. 1b. The COTS control box masses are reduced by a factor of four to reflect the change from modular, plug-and-play electronics to custom, integrated circuits. The current camera masses were doubled to reflect upgrading to space-rated cameras for a flight system. The end effector is application dependent and currently not well defined, thus an estimate was made to indicate a simple, lightweight boulder or 
surface contact pad. The other component masses are scaled based on the change in geometry of the cross-section and the link lengths. Finally, a 30\% growth factor is added to the subtotal to cover small design changes, space hardening and additional minor hardware that has not been specifically accounted for. The landing leg and grapple arm TALISMANs are estimated to have masses of $29 \mathrm{Kg}(64 \mathrm{lbs})$ and $26 \mathrm{Kg}(58 \mathrm{lbs})$, respectively, resulting in a total system mass of $166 \mathrm{Kg}$ (366 lbs) for all six TALISMANs.

\section{Conclusion}

In this paper, a structural sizing methodology and analysis code for sizing the geometry and structure of the TALISMAN system was presented. The sizing code enables the rapid investigation of the sensitivities of a design to a variety of parameters including the number, length and cross-section of the arm links; spreader height and geometry; required material properties; safety factors on strength and buckling; the lacing pattern of truss diagonals, and; tip loads and deflections. Due to the low computational requirements of the sizing code, a large number of parametric analyses can be performed on multiple sets of poses within a few minutes. The code also generates plots of the sized geometry that includes deformations and loads, and provides an output file containing parameterized sizing results from all analysis cases, from which it determines the sizing that meets all requirements for all poses. The pose cases can be obtained, for missions like the ARM, via the geometry sizing code that provides the user with the tools to quickly converge on feasible member lengths to perform the mission and provide the TALISMAN geometry to the sizing code for analysis. This initial design sizing can serve as a basis for further analysis using detailed finite element models, which may direct further cycles on the initial design via updated load requirements. Similarly, ongoing research into a TALISMAN control system could also refine the stiffness requirements, which may require further iterations on the initial design.

Results were presented that detailed the sizing of a TALISMAN capture system in application to the ARM Concept B. The masses for non-structural items, such as the joints, motors, gearboxes, electronics, and additional hardware were estimated, added to the sized structural mass and used to compute the total mass for the grapple arm and landing leg TALISMAN capture system. Finally, the derivations of the structural sizing equations, used in the customized sizing script, are presented in the attached appendix.

\section{Appendix - Derivations of Structural Sizing Formulas}

The appendix provides the derivations of the structural sizing formulas used in the MATLAB sizing code for the truss links, spreaders and tendons. The final sizing equations used in the code are highlighted with a box drawn around them.

\section{Truss Links - Longeron Buckling}

The truss links are loaded in axial compression from equilibrium with the tendon tension loads and any bending moments resolved into the truss link longerons due to out-of-plane tip loads (Fig. A1). These compressive loads are carried solely by the four longerons of the truss links. The structural efficiency of TALISMAN comes from concentrating stiffness in one-primary plane of operation (the plane-of the spreaders), thus operationally, lateral

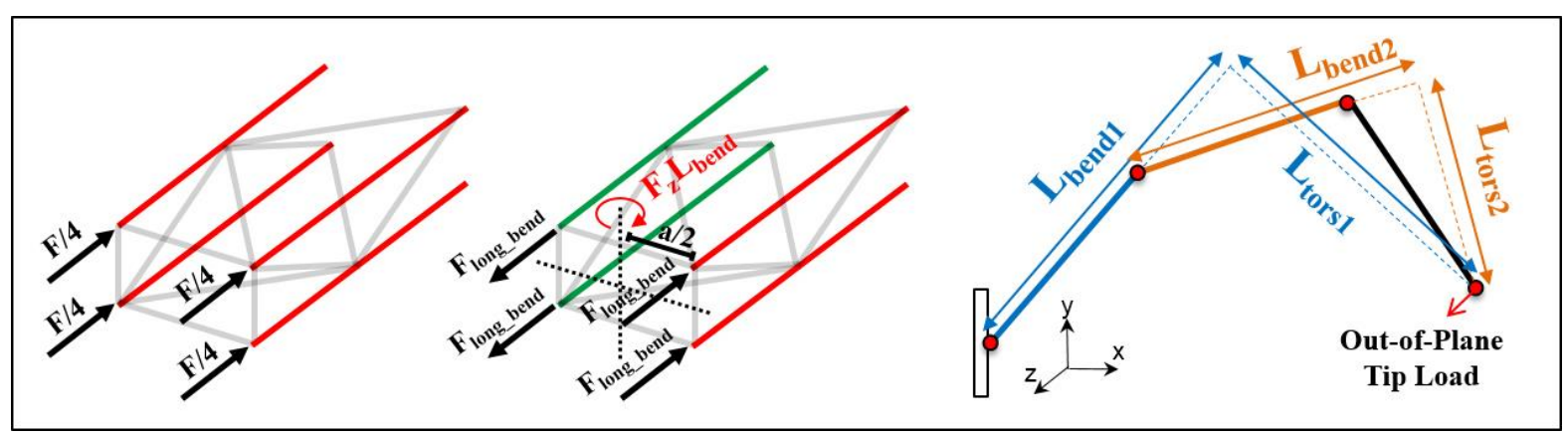

a) Axial member load. b) Bending load reacted by longerons. c) Bending and torsional moment arms

\section{Figure A1. Truss link axial loads from equilibrium with in-plane and out of plane tip loads.}

loads should be minimized. For the design case presented in this paper, a lateral load equal to $10 \%$ of the applied in- 
plane tip load is included and accounted for as detailed below when calculating the longeron buckling loads. The Euler buckling load, $P_{c r}$, with buckling factor, $B$, that accounts for end fixity is:

$$
P_{c r}=B \frac{\pi^{2} E I}{(S F)_{b} L^{2}}
$$

where $E$ is the modulus of elasticity, $I$ is the area moment of inertia, $(S F)_{b}$ is the safety factor on buckling and $L$ is the length of the member. The area moment of inertia for a square longeron of side, $t$, is:

$$
I=t^{4} / 12
$$

The longeron length, in terms of the truss width, $a$, and the truss link bay length / width ratio, $\alpha$, is:

$$
L_{\text {long }}=2 \alpha a
$$

Two loads affect the sizing of the longerons: the axial member load, $F$, (which is applied equally to all four longerons) resulting directly from equilibrium with the in-plane tip load; and the resultant axial load in each longeron, $F_{\text {long_bend }}$, induced by an applied bending moment due to an out-of-plane tip force, $F_{z}$ :

$$
F_{\text {long }}=\left(\frac{F}{4}\right)+F_{\text {long_bend }}
$$

The length of the moment arm, $L_{\text {bend }}$, is defined as the axial distance from the end of the link, being currently sized, to the tip (Fig. A1). This assumes a rigid link between the two points, which is conservative given that the arm is flexible and bending would shorten this distance. The bending load is resolved into the four longerons as:

$$
F_{z} L_{\text {bend }}=4\left[F_{\text {long_bend }}\left(\frac{a}{2}\right)\right]
$$

Where, $F_{z}$ is the out-of-plane tip load. Eq. A-5 can be solved for $F_{-}$long_bend and substituted back into Eq. A-4 to give:

$$
F_{\text {long }}=\left(\frac{F}{4}\right)+F_{\text {long_bend }}=\left(\frac{F}{4}\right)+\left(\frac{F_{z} L_{\text {bend }}}{2 a}\right)
$$

Now, Eqs. A-6, A-2 and A-3 can be substituted into Eq. A-1 to yield the wall thickness, $t_{b k l \_l}$, that meets the buckling requirement in the longerons:

$$
\begin{gathered}
\left(\frac{F}{4}\right)+\left(\frac{F_{z} L_{b e n d}}{2 a}\right)=\frac{B \pi^{2} E}{(S F)_{b}\left(4 \alpha^{2} a^{2}\right)}\left(\frac{t^{4}}{12}\right) \\
t_{b k l_{-} l}=\left[\frac{48 \alpha^{2} a^{2}(S F)_{b}}{B \pi^{2} E}\left(\frac{F}{4}+\frac{F_{z} L_{b e n d}}{2 a}\right)\right]^{1 / 4}
\end{gathered}
$$

\section{Truss Links - Diagonal Buckling}

Torque in the truss links is due solely to the out-of-plane tip load, $F_{z}$, and is resolved entirely by the diagonal members. The torsional moment arm is the normal distance, $L_{\text {tors }}$, from the end of the link to the tip (Fig. A1):

14

American Institute of Aeronautics and Astronautics 


$$
T=F_{z} L_{t o r s}
$$

In reference to Fig. A2a, the resultant load, $F$, due to an applied torque, $T$, is:

$$
F=\frac{T}{a \sqrt{1+\gamma^{2}}}
$$

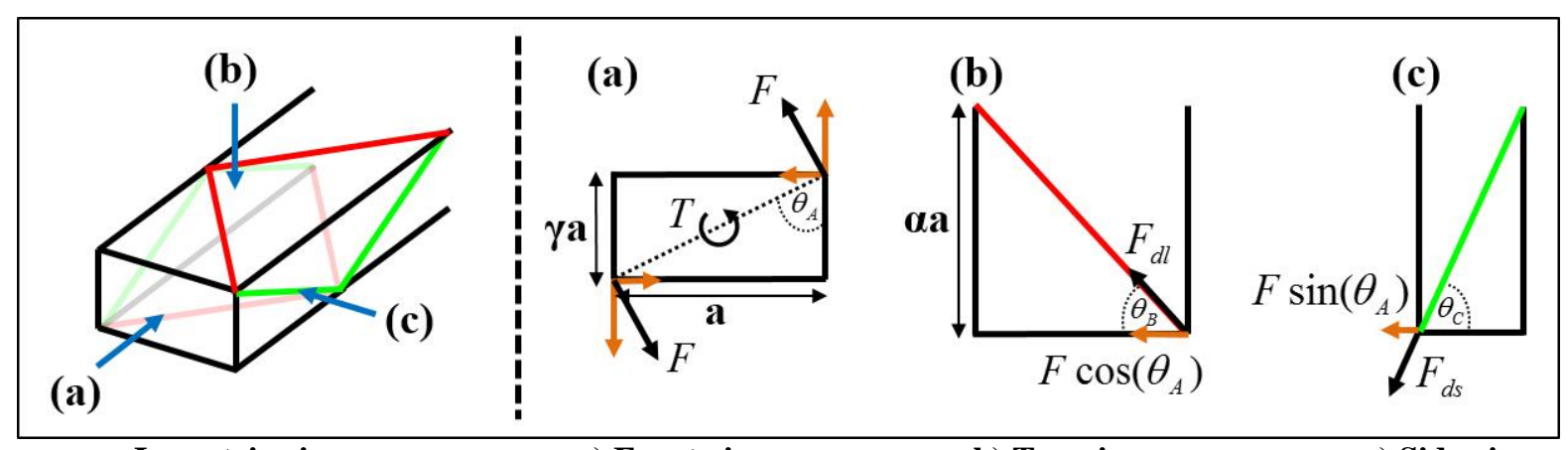

Isometric view

a) Front view.

b) Top view.

c) Side view.

Figure A2. Truss link diagonal loads from an applied torque.

The relationships between the cross-sectional link geometry and the angle of the load, $F$, are:

$$
\begin{aligned}
& \sin \left(\theta_{A}\right)=\frac{1}{\sqrt{1+\gamma^{2}}} \\
& \cos \left(\theta_{A}\right)=\frac{\gamma}{\sqrt{1+\gamma^{2}}}
\end{aligned}
$$

The angle of the long-side diagonal in Fig. A2b can be found from the relationship:

$$
\cos \left(\theta_{B}\right)=\frac{1}{\sqrt{1+\alpha^{2}}}
$$

Using Eqs. A-9, A-11 and A-12, the long diagonal force, $F_{d l}$, is:

$$
F_{d l}=\frac{F \cos \left(\theta_{A}\right)}{\cos \left(\theta_{B}\right)}=\frac{T \gamma \sqrt{1+\alpha^{2}}}{a\left(1+\gamma^{2}\right)}
$$

The angle of the short-side diagonal in Fig. A2c can be found from the relationship:

$$
\cos \left(\theta_{C}\right)=\frac{\gamma}{\sqrt{\gamma^{2}+\alpha^{2}}}
$$

Using Eqs. A-9, A-10, and A-14, the short diagonal force, $F_{d s}$, is: 


$$
F_{d s}=\frac{F \sin \left(\theta_{A}\right)}{\cos \left(\theta_{C}\right)}=\frac{T \sqrt{\gamma^{2}+\alpha^{2}}}{a \gamma\left(1+\gamma^{2}\right)}
$$

The length of the long diagonal is:

$$
L_{d l}=a \sqrt{1+\alpha^{2}}
$$

The length of the short diagonal is:

$$
L_{d s}=a \sqrt{\gamma^{2}+\alpha^{2}}
$$

Using Eq. A-1, and substituting in; the long diagonal force from Eq. A-13; the area moment of inertia from Eq. A-2; and the long diagonal length from Eq. A-16, yields the wall thickness that meets the buckling requirement in the long diagonals:

$$
\begin{gathered}
\frac{T \gamma \sqrt{1+\alpha^{2}}}{a\left(1+\gamma^{2}\right)}=\frac{B \pi^{2} E t^{4}}{12(S F)_{b} a^{2}\left(1+\alpha^{2}\right)} \\
t_{b k l_{-} d l}=\left[\frac{12(S F)_{b} T \gamma a\left(1+\alpha^{2}\right)^{3 / 2}}{B \pi^{2} E\left(1+\gamma^{2}\right)}\right]^{1 / 4}
\end{gathered}
$$

Similarly, using Eq. A-1, and substituting in; the short diagonal force and length from Eqs. A-15 and A-17; and the area moment of inertia from Eq. A-2, yields the wall thickness that meets the buckling requirement in the short diagonals:

$$
t_{b k l_{-} d s}=\left[\frac{12(S F)_{b} T a\left(\gamma^{2}+\alpha^{2}\right)^{3 / 2}}{B \pi^{2} E \gamma\left(1+\gamma^{2}\right)}\right]^{1 / 4}
$$

\section{Truss Links - Ultimate Stress Longerons and Diagonals}

The ultimate stress, $\sigma_{s}$, of the longerons and diagonals is determined according to Eq. A-20, where $(S F)_{s}$ is the safety factor on strength, and the load, $F$, is replaced by the forces from one of Eqs. A-4, A-13 or A-15:

$$
\sigma_{s}=\frac{(S F)_{s} F}{A}
$$

The cross-sectional area of the longerons and diagonals is:

$$
A=t^{2}
$$

Rearranging Eq. A-20, and substituting in Eq. A-21 yields the wall thickness sized for the ultimate strength requirement:

$$
t_{s t r}=\sqrt{\frac{(S F)_{s} F}{\sigma_{s}}}
$$




\section{Truss Links - Mass Calculation}

The truss link mass is calculated by determining the total length of all of its longerons, diagonals and the two end frames (i.e. the two rectangles at the end of each link, shown in Fig. A2b and multiplying by the density and area. The perimeter length of the end frames is:

$$
L_{e n d s}=4 a+4 \gamma a
$$

and the total length of the longerons and diagonals for a single truss bay is:

$$
L_{b a y}=4 \alpha a+2 L_{d l}+2 L_{d s}
$$

where $L_{d l}$ and $L_{d s}$ were determined in Eqs. A-16 and A-17. To find the total length of all local truss members, $L_{b a y}$ is multiplied by the total link length, $L$, divided by the bay length, $\alpha a$, then added to $L_{\text {ends }}$. The total mass is then:

$$
\begin{gathered}
M=\rho A L=\rho t^{2}\left[\left(\frac{L}{\alpha a}\right) L_{b a y}+L_{\text {ends }}\right] \\
M_{\text {link }}=2 \rho t^{2}\left[\frac{L}{\alpha}\left(2 \alpha+\sqrt{1+\alpha^{2}}+\sqrt{\gamma^{2}+\alpha^{2}}\right)+2 a(1+\gamma)\right]
\end{gathered}
$$

\section{Spreaders - Area and Mass}

The spreaders are I-beams with an inner width of $a$ (the width of the truss links), flange width, $W$, and a wall thickness of $t$. The cross-sectional area and mass of the closed-section side of a spreader with height, $h_{c s}$, are:

$$
\begin{gathered}
A=2 W t+a t \\
M=\rho t(2 W+a) h_{c s}
\end{gathered}
$$

and the open-section side of a spreader has the following cross-sectional area and mass, where $d_{t}$ is the tab width (shown in Fig. 2c) and $h_{o s}$ is the open-section side height:

$$
A=2 W t+2 d_{t} t
$$

$$
M=2 \rho t\left(2 W+d_{t}\right) h_{o s}
$$

\section{Spreaders - Lateral Buckling due to Axial Compression}

The area moments of inertia for the spreaders are found by applying the parallel axis theorem in Eq. A-30. The parallel axis theorem divides the I-beam into rectangular areas, $A_{i}$, with parallel axes at distances, $\delta_{\mathrm{yi}}$ from the centroidal axis of the I-beam. The theorem is written:

$$
I_{x}=\sum_{i=1}^{n} I_{x i}+A_{i} \delta_{y i}^{2}
$$

The spreaders have a strong and weak direction in bending. The strong direction is in the plane of the webbing (i.e. out of plane with respect to the TALISMAN, about the x-axis), while the weak direction is in the plane of the 
flanges (about the z-axis), which are typically shorter than the webbing width, $a$. For the closed-section side of the Ibeam spreader, the following area moments of inertia are obtained:

$$
\begin{aligned}
& I_{x}=\frac{t a^{3}}{12}+2\left[\frac{W t^{3}}{12}+W t\left(\frac{a+t}{2}\right)^{2}\right] \\
& I_{z}=\frac{a t^{3}}{12}+\frac{2 t W^{3}}{12}=\frac{t}{12}\left(a t^{2}+2 W^{3}\right)
\end{aligned}
$$

Likewise, the area moments of inertia for the open-section side of the spreader are:

$$
\begin{gathered}
I_{x}=2\left[\frac{t d_{t}^{3}}{12}+d_{t} t\left(\frac{a-d_{t}}{2}\right)^{2}\right]+2\left[\frac{W t^{3}}{12}+W t\left(\frac{a+t}{2}\right)^{2}\right] \\
I_{x}=\frac{d_{t} t}{6}\left[d_{t}^{2}+3\left(a-d_{t}\right)^{2}\right]+\frac{W t}{6}\left[t^{2}+3(a+t)^{2}\right] \\
I_{z}=\frac{2 d_{t} t^{3}}{12}+\frac{2 t W^{3}}{12}=\frac{t}{6}\left(d_{t} t^{2}+W^{3}\right)
\end{gathered}
$$

Rearranging Eq. 1 in terms of the area moment of inertia, and substituting in Eq. A-31, and the height of the closedsection side of the spreader, $h_{c s}$, for $L$, the sizing equation for $W$, based on buckling for the closed-section side of the spreaders in the strong direction (about the $\mathrm{x}$-axis) is:

$$
\begin{gathered}
\frac{F(S F)_{b} h_{c s}{ }^{2}}{B \pi^{2} E}=\frac{t a^{3}}{12}+2 W t\left[\frac{t^{2}}{12}+\left(\frac{a+t}{2}\right)^{2}\right] \\
\frac{12 F(S F)_{b} h_{c s}{ }^{2}-B \pi^{2} a^{3} E t}{B \pi^{2} E t}=24 W\left[\frac{t^{2}}{12}+\left(\frac{a+t}{2}\right)^{2}\right] \\
W_{b k l_{-} c s_{-} x}=\frac{12 F(S F)_{b} h_{c s}{ }^{2}-B \pi^{2} a^{3} E t}{B \pi^{2} E t\left(2 t^{2}+6(a+t)^{2}\right)}
\end{gathered}
$$

Similarly in the weak direction (about the z-axis), substituting in Eq. A-32 instead, the sizing equation is:

$$
\begin{gathered}
\frac{F(S F)_{b} h_{c s}{ }^{2}}{B \pi^{2} E}=\frac{t}{12}\left(a t^{2}+2 W^{3}\right) \\
W_{b k l_{-} c s_{-} z}=\left[\frac{6 F(S F)_{b} h^{2}}{B \pi^{2} E t}-\frac{a t^{2}}{2}\right]^{1 / 3}
\end{gathered}
$$

For the open-section side with height, $h_{o s}$, the strong direction sizing equation for buckling is: 


$$
\begin{gathered}
\frac{F(S F)_{b} h_{o s}{ }^{2}}{B \pi^{2} E}=\frac{d_{t} t}{6}\left[d_{t}{ }^{2}+3\left(a-d_{t}\right)^{2}\right]+\frac{W t}{6}\left[t^{2}+3(a+t)^{2}\right] \\
W_{b k l_{-} o s_{-} x}=\frac{6 F(S F)_{b} h_{o s}{ }^{2}-B \pi^{2} E d_{t} t\left(d_{t}{ }^{2}+3\left(a-d_{t}\right)^{2}\right)}{B \pi^{2} E t\left(t^{2}+3(a+t)^{2}\right)}
\end{gathered}
$$

and in the weak direction:

$$
\begin{gathered}
\frac{F(S F)_{b} h_{o s}{ }^{2}}{B \pi^{2} E}=\frac{t}{6}\left(d_{t} t^{2}+W^{3}\right) \\
W_{b k l_{-} o s_{-} z}=\left[\frac{6 F(S F)_{b} h_{o s}{ }^{2}}{B \pi^{2} E t}-d_{t} t^{2}\right]^{1 / 3}
\end{gathered}
$$

\section{Spreaders -Torsional Buckling due to Axial Compression}

The torsional stiffness, $\mathrm{GI}_{\mathrm{o}}$, and warping stiffness, $\mathrm{C}_{\mathrm{w}}$, for the closed-section side of the spreader are defined as:

$$
\begin{gathered}
G I_{o}=\frac{G t^{3}}{3}(2 W+a) \\
C_{\omega}=\frac{(a+2 t)^{2} t W^{3}}{24}
\end{gathered}
$$

The warping stiffness, $\mathrm{C}_{\mathrm{w}}$, for the open-section of the spreader is the same as Eq. A-40, while the torsional stiffness for the open-section is defined as:

$$
G I_{o}=\frac{2 G}{3}\left(W t^{3}+t d_{t}^{3}\right)
$$

The polar area moment of inertia is defined in Eq. A-42. The area moments of inertia for the closed and open section sides of the I-beam spreaders in Eqs. A-31 and A-32, and in Eqs. A-33b and A-34, respectively, can be substituted into Eq. A-43 and, then through substitution of the appropriate cross-sectional area from Eqs. A-26 or A-28, can be used to size the flange width based on torsional buckling:

$$
\begin{gathered}
I_{o}=I_{x}+I_{z} \\
(S F)_{b} F=\frac{A}{I_{o}}\left(C+C_{1} \frac{\pi^{2}}{L^{2}}\right)
\end{gathered}
$$

\section{Spreaders - Ultimate Stress}

The spreaders can experience both tension and compression during normal operations as the joint angles vary, therefore the ultimate strength of the materials used for the spreader must be defined in both tension and 
compression. The general sizing equation for the critical stress was defined in Eq. A-20. Rearranging this equation to equate to the cross-sectional area and substituting in Eq. A-26 for the closed-section side of the spreader gives:

$$
\begin{gathered}
\frac{(S F)_{s} F}{\sigma_{s}}=t(2 W+a) \\
W_{s t r_{-} c s}=\frac{(S F)_{s} F}{2 \sigma_{s} t}-\frac{a}{2}
\end{gathered}
$$

and for the open-section side, where Eq. A-28 is substituted into Eq. A-20 it follows:

$$
\begin{gathered}
\frac{(S F)_{s} F}{\sigma_{s}}=2 t\left(W+d_{t}\right) \\
W_{s t r_{-} o s}=\frac{(S F)_{s} F}{2 \sigma_{s} t}-d_{t}
\end{gathered}
$$

\section{Tendons - Ultimate Stress}

Since the tendons only experience tension, only the ultimate strength equation is required for sizing:

$$
\begin{gathered}
\frac{(S F)_{s} F}{\sigma_{s}}=\pi R^{2} \\
R=\sqrt{\frac{(S F)_{s} F}{\pi \sigma_{s}}}
\end{gathered}
$$

\section{References}

${ }^{1}$ Dorsey, J. T., Mikulas, M. M., and Doggett, W. R., "Preliminary Structural Design Considerations and Mass Efficiencies for Lunar Surface Manipulator Concepts." Proceedings of the AIAA Space 2008 Conference and Exposition, San Diego CA, 2008.

${ }^{2}$ Dorsey, J. T. et al., "Recent Developments in the Design, Capabilities and Autonomous Operations of a Lightweight Surface Manipulation System and Test-bed." Proceedings of the AIAA Space 2011 Conference and Exposition, Long Beach CA, 2011.

${ }^{3}$ Doggett, W. R., Dorsey, J. T., Jones, T. C., and King, B., "Development of a Tendon-Actuated Lightweight In-Space MANipulator (TALISMAN)." Proceedings of the 42nd Aerospace Mechanisms Symposium, NASA Goddard Space Flight Center, Greenbelt MD, 2014.

${ }^{4}$ Dorsey J. T., Doggett W. R. et. al., "Application of a Novel Long-Reach Manipulator Concept to Asteroid Redirect Missions," Proceedings of the AIAA 2015 SciTech Conference, Kissimmee FL, 2015.

${ }^{5}$ Doggett, W. R., Dorsey, J. T., Jones, T. C., "Overview of Recent Updates to TALISMAN.” Proceedings of the AIAA Space 2015 Conference and Exposition (in preparation), Pasadena CA, 2015.

${ }^{6}$ Altenbuchner, C., Dorsey, J. T., Jones, T. C., "Dynamic Response Characteristics of a Robotic Manipulator-Based Capture System Performing the Asteroid Redirect Mission," Proceedings of the AIAA Space 2015 Conference and Exposition (in preparation), Pasadena CA, 2015.

${ }^{7}$ Altenbuchner, C., Dorsey, J. T., Jones, T. C., "Flexible Multibody Dynamic Modeling of Tendon-Actuated Lightwight InSpace Manipulator (TALISMAN)," Proceedings of the AIAA Space 2015 Conference and Exposition (in preparation), Pasadena CA, 2015.

${ }^{8}$ Komendera, E. E., Doggett, W. R., Dorsey, J. T., Debus, T. J., Holub, K. and Dougherty, S. P., "Control System Design Implementation and Preliminary Demonstration for a Tendon-Actuated Lightweight In-Space MANipulator (TALISMAN)," Proceedings of the AIAA Space 2015 Conference and Exposition (in preparation), Pasadena CA, 2015. 
${ }^{9}$ Crocker, L., NASA JSC 28918 - "EVA Design Requirements and Considerations”, Johnson Space Center, Houston TX, 2005.

${ }^{10}$ Maciejewski, A. A., and Klein, C. A., "Obstacle Avoidance for Kinematically Redundant Manipulators in Dynamically Varying Environments,” The International Journal of Robotics Research V4, No. 3 (1985): pp. 109-117.

${ }^{11}$ Klein, C., and Huang, C-H., "Review of Pseudoinverse Control for Use with Kinematically Redundant Manipulators," Systems, Man and Cybernetics, IEEE Transactions on 2 (1983): 245-250.

${ }^{12}$ Reeves D. M., Naasz, B. J., Wright, C. A., and Pini, A. J., "Proximity Operations for the Robotic Boulder Capture Option for the Asteroid Redirect Mission," Proceedings of the AIAA Space 2014 Conference and Exposition, San Diego, CA, Aug 2014.

${ }^{13}$ Llanos, P. J., Miller, J. K., and Hintz, G. R., "Orbital Evolution and Environmental Analysis Around Asteroid 2008 EV5," American Astronautical Society National Conference, AAS 14-360, February, 2014.

${ }^{14}$ Busch, M. W., et al., "Radar Observations and the Shape of Near-Earth Asteroid 2008 EV5," Icarus 212.2 (2011): pp. 649660. 